\title{
Borehole Stability in Shale Formation for Extended Reach Wells
}

\author{
Zhao Kai*, Deng Jin-Gen, Tan Qiang, Yu Bao-Hua, Yuan Jun-Liang, Zhu Hai-Yan and Wang Ying
}

Key Laboratory of Petroleum Engineering, Ministry of Education, China University of Petroleum, Beijing, China, 102249

\begin{abstract}
In recent years, Extended reach well (ERW) drilling technology is widely used in the offshore oil \& gas fields in order to reduce the number of the drilling platforms. As it has notable characteristics such as the high deviation angle, large horizontal displacement and long open borehole interval the borehole stability increases the drilling risk and cost dramatically. To research the ERW borehole stability, including mechanical model, shale hydration test and the effect of circulating pressure loss in this paper, rock mechanics theory and hydraulics principle were comprehensively applied . The results show that, the safer drilling azimuth of the ERW in normal fault lies in the minimum horizontal principle stress direction; hydration radius increases with the passage of time, and the hydration collapsed rock has important influence on cutting beds and circulating pressure loss in annulus; the upper limit value of safety mud density decreases with the well depth increases, and when it deceases to the equivalent mud density of collapse pressure, the limit depth of the ERW is obtained. The research results provide relevant guidance on the ERW drilling, which can be used to determine the upper and lower safety mud weight limits, the best well trajectory selections and the well structure design.
\end{abstract}

Keywords: ERW, borehole stability, circulating pressure loss, hydration, cuttings bed.

\section{INTRODUCTION}

With the rapid development of world oil industry, in recent years the drilling technology of ERW has been more and more applied into drilling practices. This technology has been mainly used in the development of marginal oilfields, and especially for offshore oilfields [1], which represents the peak of drilling technology in the world today. However, due to the well deflection, hydration in shale formation and higher ECD, borehole stability becomes one of the difficult points in the ERW drilling. Comprehensive researches on the borehole stability of ERW with the rock mechanics theory and hydraulics principle are of great importance to ERW drilling.

Over the years, although a large number of models for borehole stability have been developed [2-5], the focus of these models was generally on the mechanical analysis, the influence of hydraulics factors has been paid little attention, which often leads to a serious drilling accident such as the drilling fluid leakage in the ERW. In addition, due to neglecting shale hydration, the formation strength and the solid concentration in annulus are both regarded relatively conservatively [6], which leads to some errors for the selection of safety mud density. Considering the well deviation and azimuth angle, shale hydration and the effectof circulating pressure loss, a new analytical model was established in this paper, and the borehole stability for ERD was studied further.

\footnotetext{
*Address correspondence to this author at the Key Laboratory of Petroleum Engineering, Ministry of Education, China University of Petroleum, Beijing, 18\# Fuxue Road, Changping, Beijing 102249, China; Tel: 010-89733911 turn 22; Fax: 86.1089733155;

E-mail: zkaiup@126.com
}

\section{MECHANICS MECHANISM OF BOREHOLE IN- STABILITY OF ERW}

In order to study the mechanics mechanism of borehole instability of ERW, we should start from the stress field around the borehole, choose the proper failure model, and finally determine the reasonable mud density to stabilize the borehole. For an ERW, because of the borehole slopes, the borehole trajectory has a significant influence on the borehole stability.

\subsection{Stress State Around the Borehole}

After borehole is drilled, the stress around the borehole redistributes, and concentrates as the model of infinite plate with a small hole. Under the principle of general plane strain, for small deformation, we can get the stress balance equation, the geometric equation and the boundary conditions on the borehole wall:

$$
\begin{aligned}
& \sigma_{i j, j}+f_{i}=0 \\
& \varepsilon_{i j}=\frac{1}{2}\left(u_{i, j}+u_{j, i}\right) \\
& \sigma_{r}=p_{w}
\end{aligned}
$$

Where $p_{w}$ is the mud column pressure, $\mathrm{MPa}$;

For an ERW, the in situ stress tensor in the borehole coordinate system [7] can be obtained through the coordinate transformation Fig. (1):

$[\sigma]=[L]\left[\begin{array}{ccc}\sigma_{H} & 0 & 0 \\ 0 & \sigma_{h} & 0 \\ 0 & 0 & \sigma_{v}\end{array}\right][L]^{T}$ 


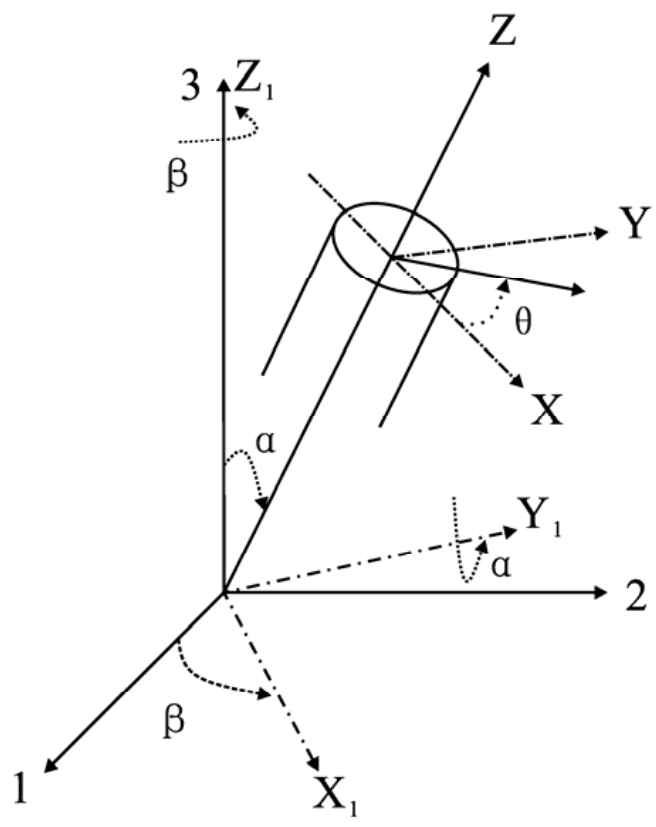

Fig. (1). The coordinate transformation of an ERW axis.

Where: $\sigma_{V}, \sigma_{H}, \sigma_{h}$ are the overburden pressure, maximum and minimum horizontal in situ stresses respectively, $\mathrm{MPa} ; \alpha$ is well azimuth angle, $\operatorname{deg} ; \beta$ is well deviation angle, deg; $[L]$ is the transformation matrix of well deviation angle and well azimuth angle [2]:

$[L]=\left[\begin{array}{ccc}\cos \alpha \cos \beta & \cos \alpha \sin \beta & -\sin \beta \\ -\sin \beta & \cos \beta & 0 \\ \sin \alpha \cos \beta & \sin \alpha \cos \beta & \cos \beta\end{array}\right]$

The coordinate transformation from the principal in situ stress coordinate system $(1,2,3)$ to the borehole coordinate system $(\mathrm{X}, \mathrm{Y}, \mathrm{Z})$ is realized by the two steps Fig. (1):

1) According to the right hand rule, taking coordinate axis 3 as fixed axis, the coordinate system $\left(\mathrm{X}_{1}, \mathrm{Y}_{1}, \mathrm{Z}_{1}\right)$ is gained by rotating the coordinate system $(1,2,3)$ by $\beta$. The first $\beta$ nearby the coordinate axis 3 is considered as the fixed axis, but the second $\beta$ between the coordinate axis 1 and $\mathrm{X}_{1}$ is the magnitude of rotating angel.

2) According to the right hand rule, taking coordinate axis $\mathrm{Y}_{1}$ as fixed axis, the coordinate system $(\mathrm{X}, \mathrm{Y}, \mathrm{Z})$ is gained by rotating the coordinate system $\left(\mathrm{X}_{1}, \mathrm{Y}_{1}, \mathrm{Z}_{1}\right)$ by $\alpha$. The first $\alpha$ nearby the coordinate axis $\mathrm{Y}_{1}$ is considered as the fixed axis, but the second $\alpha$ between the coordinate axis $\mathrm{Z}_{1}$ and $\mathrm{Z}$ is taken as the magnitude of rotating angel.

From equations $(1) \sim(5)$, under the linear elastic assumption, the total stress distribution around the borehole can be obtained through the contribution of the in situ stress in borehole coordinate system, formation pore pressure, and mud column pressure:

$$
\begin{aligned}
\sigma_{r}= & \frac{R^{2}}{r^{2}} P+\frac{\left(\sigma_{x x}+\sigma_{y y}\right)}{2}\left(1-\frac{R^{2}}{r^{2}}\right)+\frac{\left(\sigma_{x x}-\sigma_{y y}\right)}{2}\left(1+\frac{3 R^{4}}{r^{4}}-\frac{4 R^{2}}{r^{2}}\right) \cos 2 \theta \\
& +\sigma_{x y}\left(1+\frac{3 R^{4}}{r^{4}}-\frac{4 R^{2}}{r^{2}}\right) \sin 2 \theta+\delta\left[\frac{\alpha(1-2 v)}{2(1-v)}\left(1-\frac{R^{2}}{r^{2}}\right)-\phi\right]\left(P-P_{p}\right)
\end{aligned}
$$

$$
\begin{aligned}
\sigma_{\theta}= & -\frac{R^{2}}{r^{2}} P+\frac{\left(\sigma_{x x}+\sigma_{y y}\right)}{2}\left(1+\frac{R^{2}}{r^{2}}\right)-\frac{\left(\sigma_{x x}-\sigma_{y y}\right)}{2}\left(1+\frac{3 R^{4}}{r^{4}}\right) \cos 2 \theta \\
& -\sigma_{x y}\left(1+\frac{3 R^{4}}{r^{4}}-\frac{4 R^{2}}{r^{2}}\right) \sin 2 \theta+\delta\left[\frac{\alpha(1-2 v)}{2(1-v)}\left(1-\frac{R^{2}}{r^{2}}\right)-\phi\right]\left(P-P_{p}\right) \\
\sigma_{z}= & \sigma_{z z}-v\left[2\left(\sigma_{x x}-\sigma_{y y}\right)\left(\frac{R}{r}\right)^{2} \cos 2 \theta+4 \sigma_{x y}\left(\frac{R}{r}\right)^{2} \sin 2 \theta\right] \\
& +\delta\left[\frac{\alpha(1-2 v)}{1-v}-\phi\right]\left(P-P_{p}\right) \\
\sigma_{r \theta}= & \sigma_{x y}\left(1-\frac{3 R^{4}}{r^{4}}+\frac{2 R^{2}}{r^{2}}\right) \cos 2 \theta \\
\sigma_{\theta z}= & \sigma_{y z}\left(1+\frac{R^{2}}{r^{2}}\right) \cos \theta-\sigma_{x z}\left(1+\frac{R^{2}}{r^{2}}\right) \sin \theta \\
\sigma_{z r}= & \sigma_{x z}\left(1-\frac{R^{2}}{r^{2}}\right) \cos \theta+\sigma_{y z}\left(1-\frac{R^{2}}{r^{2}}\right) \sin \theta
\end{aligned}
$$

Where $\sigma_{r}, \sigma_{\theta}, \sigma_{z}, \sigma_{r \theta}, \sigma_{\theta z}, \sigma_{r z}$ are the stress components around the borehole in borehole cylindrical coordinate system, MPa; $\sigma_{x x}, \sigma_{y y}, \sigma_{z z}, \sigma_{x y}, \sigma_{x z}, \sigma_{y z}$ are the stress components of $[\sigma], \mathrm{MPa} ; \mathrm{P}$ is mud column pressure, $\mathrm{MPa}$; $\mathrm{P}_{\mathrm{p}}$ is formation pore pressure, $\mathrm{MPa} ; \mathrm{R}$ is borehole radius, $\mathrm{m} ; \mathrm{r}$ is the distance from the formation to the hole center, $\mathrm{m}$, $\theta$ is the well round angle, $\operatorname{deg} ; \boldsymbol{v}$ is Poisson ratio; $\phi$ is rock porosity, $\% ; \alpha$ is effective stress coefficient.

\subsection{Mechanics Mechanism of Borehole Instability}

After borehole is drilled, the initial rock support is replaced by mud column pressure. When the mud column pressure is lower, collapse instability occurs on the sidewall surrounding rock because the stress is beyond the shear strength. Generally, Mohr-Coulomb principle is used as the criterion of collapse instability:

$$
f=\left(\sigma_{1}-\sigma_{3}\right)-\sin \varphi\left(\sigma_{1}+\sigma_{3}\right)-2 C \cos \varphi=0
$$

Where $\sigma_{1}$ is the maximum principal stress, $\mathrm{MPa} ; \sigma_{3}$ is the minimum principal stress, $\mathrm{MPa} ; \mathrm{C}$ is the rock cohesion, $\mathrm{MPa} ; \varphi$ is the rock internal friction angle, deg.

From the formula (6), we can see that $\sigma_{r}$ is a principal stress on the borehole wall, the other two principal stresses can be expressed as:

$$
\sigma_{a, b}=\frac{\sigma_{z}+\sigma_{\theta}}{2} \pm \sqrt{\left[\frac{\sigma_{z}-\sigma_{\theta}}{2}\right]^{2}+\sigma_{\theta z}^{2}}
$$

So, the maximum and minimum principal stress on the borehole wall is:

$\sigma_{1}=\max \left(\sigma_{a}, \sigma_{b}, \sigma_{r}\right) ; \sigma_{3}=\min \left(\sigma_{a}, \sigma_{b}, \sigma_{r}\right)$

Taking the calculated the maximum and minimum principal stress on the borehole wall into the Mohr-Coulomb equation, we can calculate the minimum mud density to keep borehole stability.

On the contrary, when the mud column pressure is higher, the tangential stress on the borehole wall will become 
Table 1. Experimental results of shale hydration.

\begin{tabular}{|c|c|c|c|c|c|c|}
\hline \multirow{4}{*}{$\begin{array}{l}\text { The distance to the } \\
\text { core end face, } x(\mathrm{~cm})\end{array}$} & 1core & 1.0 & 2.0 & 3.0 & 4.0 & 5.0 \\
\hline & 3 core & 1.4 & 2.8 & 4.2 & & \\
\hline & 4 core & 1.6 & 3.2 & 4.8 & & \\
\hline & 5 core & 1.8 & 3.6 & & & \\
\hline \multirow{4}{*}{ Water content, w (\%) } & 2 core & 5.72 & 4.31 & 2.91 & 2.23 & \\
\hline & 3 core & 5.42 & 3.62 & 2.52 & & \\
\hline & 4 core & 5.12 & 3.24 & 2.23 & & \\
\hline & 5 core & 4.84 & 2.91 & & & \\
\hline
\end{tabular}

Table 2. Experimental results of uniaxial compressive strength.

\begin{tabular}{|c|c|c|c|c|c|c|c|}
\hline Water content, $\mathbf{w}(\boldsymbol{\%})$ & 0.38 & 1.22 & 2.58 & 3.67 & 4.95 & 5.38 & 6.22 \\
\hline The uniaxial compressive strength $(\mathbf{M P a})$ & 12.68 & 10.57 & 8.66 & 6.54 & 4.32 & 2.17 & 0.82 \\
\hline
\end{tabular}

the tensile stress, and when it is beyond the tensile strength, the rock tensile failure on the borehole wall will occur:

$\sigma_{\theta}=-S_{t}$

Where $\sigma_{\theta}$ is the tangential stress on the borehole wall, $\mathrm{MPa} ; \mathrm{S}_{\mathrm{t}}$ is the rock tensile strength, $\mathrm{MPa}$.

According to the stress distribution of borehole, and combining with failure criterions which are given in equations $(7) \sim(10)$, safe mud density can be obtained for stabilizing borehole.

\section{LABORATORY EXPERIMENT OF SHALE HY- DRATION}

When drilling with water-based mud, hydration will occur in the shale formation which reduces the rock strength. In macroscopic view, it is mainly manifested as the water content which has an effect on the shale strength. In drilling process, the water and ion in drilling mud will transport in and out of the formation under the driving pressure difference and chemical potential difference between the drilling mud and the formation fluid. The water absorption process is very complex. Supposing that adsorbed water can diffuse freely, and then the adsorbed water diffusion can be simulated as the thermal diffusion. According to the law of mass conservation, the regular distribution of the total absorption water varying with time and space was obtained by combining with the initial conditions and boundary conditions [8]:

$W(r, t)=W_{0}+\left(W_{s}-W_{0}\right)\left[1+\int_{0}^{a} e^{-C_{f} \cdot \zeta^{2} \cdot t} \frac{J_{0}(\xi r) Y_{0}(\xi a)-Y_{0}(\xi r) J_{0}(\xi a)}{J_{0}^{2}(\xi a)+Y_{0}^{2}(\xi a)} \cdot \frac{d \zeta}{\zeta}\right]$

Where $W_{0}$ is the original water content in the formation, $\% ; W_{s}$ is saturated water content $\mathrm{n}, \% ; J_{0}(\xi r)$ and $Y_{0}(\xi \alpha)$ are the first zero-order Bessel function and the second zeroorder Bessel function respectively; $C_{f}$ is the adsorbed water diffusion coefficient.

It is the key to determine the value of $C_{f}$ through shale hydration test which is conducted under the real downhole pressure and temperature simulation. The experimental process is shown as followed:

A) Measure the original water content of the core, then process to the standard size with $\varphi 25 \mathrm{~mm}$.

B) Set the standard core into the core holder and drilling fluid into the tank.

C) Add the confining pressure to a predetermined value (10MPa in this experiment), the axial pressure to the experimental value ( $5 \mathrm{MPa}$ in this experiment).

D) Open the hydraulic pump, make sure the drilling fluid reaches the core end plane, and keep the driving pressure stable, then begin timing.

E) EAfter the experimental time reaches a predetermined value (5-6 days in this experiment), unload pressure, and remove the rock sample quickly, then cut the sample with a certain distance along the axial direction, measure the water content with the drying and weighing method.

Under laboratory conditions, shale hydration is onedimensional propagation, the change law of absorption water with time and space can be simplified to:

$$
W(x)=W_{0}+\left(W_{s}-W_{0}\right) \operatorname{erfc}\left(\frac{x}{2 \sqrt{C_{f} t}}\right)
$$

Where $x$ is the distance to core end plane, $\mathrm{cm}$.

The experimental results are shown in Table $\mathbf{1}$ According to the least square method to fit the experimental data Fig. (2), We can get $C_{f}=0.0331 \mathrm{~cm}^{2} / \mathrm{h}$, then the 


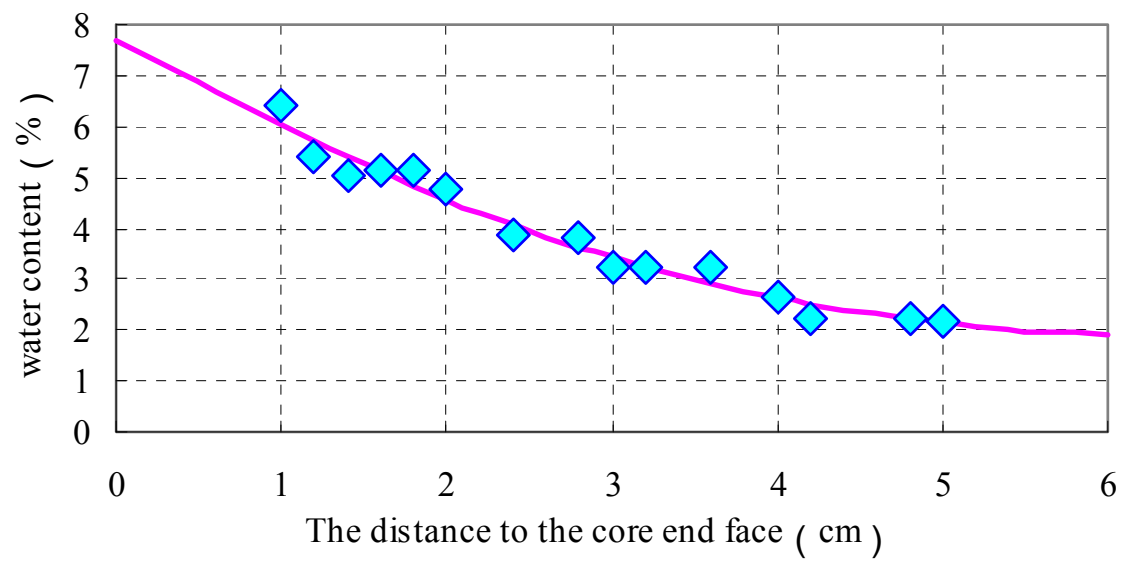

Fig. (2). The experimental result of shale hydration.

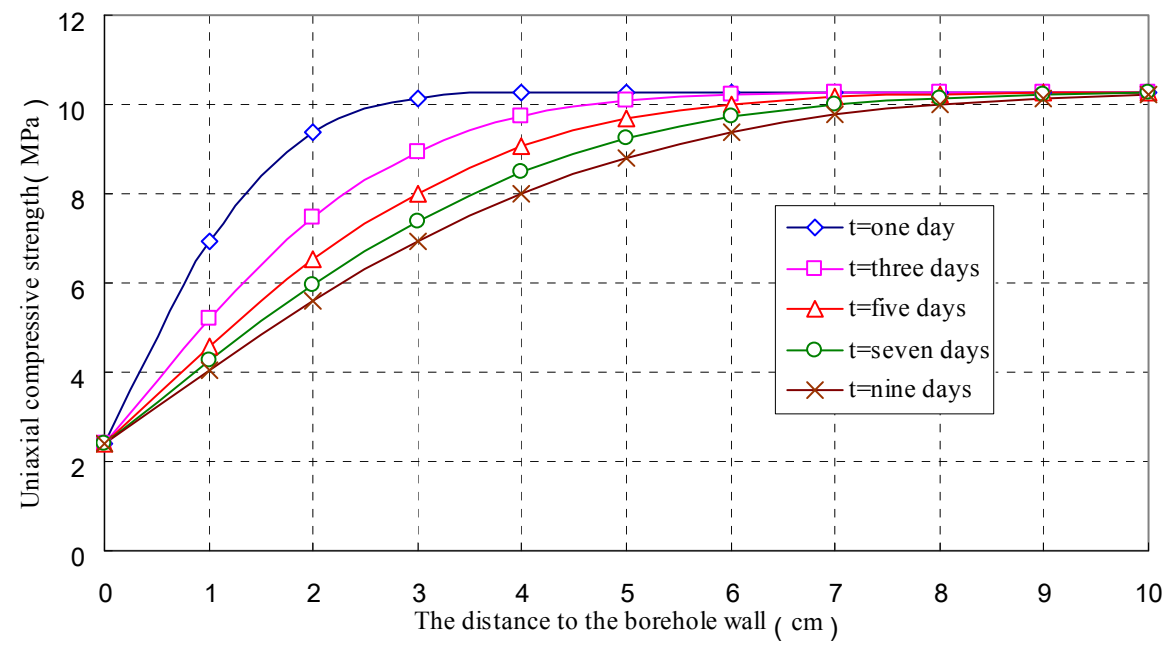

Fig. (3). The change law of shale strength with time and space.

change law of water content with time and space can be calculated. In order to study the relation between water content and formation strength, laboratory tests of the field cores were carried out. The water content of the field cores was measured, and the cores were processed to standard size with the diameter of $25 \mathrm{~mm}$ and the slenderness ratio of 1.8 2. Then the standard cores with different water content were performed with uniaxial compression, and their uniaxial compressive strength with different water content was obtained. The experimental results of uniaxial compressive strength of cores with different water content are shown in Table 2. By using simple linear regression, the relationship between water content and formation strength that is observed is as follows:

$U C S=-198.63 w+13.461$

Where $U C S$ is the rock uniaxial compressive strength, $\mathrm{MPa}$; $w$ is water content, $\%$.

According to the equations (12) (13), the change law of formation strength with time and space is shown in Fig. (3), From which it is realized that as the time goes on, the influence radius of hydration will be bigger. So, more and more rock around borehole will go into bore hole, which has a great influence on cutting beds and circulating pressure loss in annulus.

\section{THE SAFE MUD DENSITY WINDOW WHEN CON- SIDERING CIRCULATING PRESSURE LOSS IN AN- NULUS}

The actual pressure that mud column acts on formation is constituted by the hydrostatic mud column pressure and surge pressure. During mud circulation process, the well bottom pressure equals to the sum of hydrostatic mud column pressure and the circulating pressure loss in annulus, however, when stopping pump it is equal to the hydrostatic mud column pressure. For the ERW, due to the long well depth and large pressure loss, the difference of the well bottom pressure between circulation process and stopping pump process cannot be ignored. In order to keep borehole stability during the whole drilling process, the lower and upper limit of safe mud density should be equal to the collapse pressure when stopping pump and the fracture pressure while drilling fluid is circulating respectively. In view of the collapse pressure resolved as the safe mud density lower limit in chapter one, the key is to calculate the safe mud density upper limit.

When there is no cuttings bed in the borehole, the calculation formula of eccentric annulus pressure loss is shown as follows:

$\Delta p_{a}=\frac{19.6 f_{m} \rho_{m} L_{a} V_{a}^{2}}{D_{h e}-D_{p o}}$ 


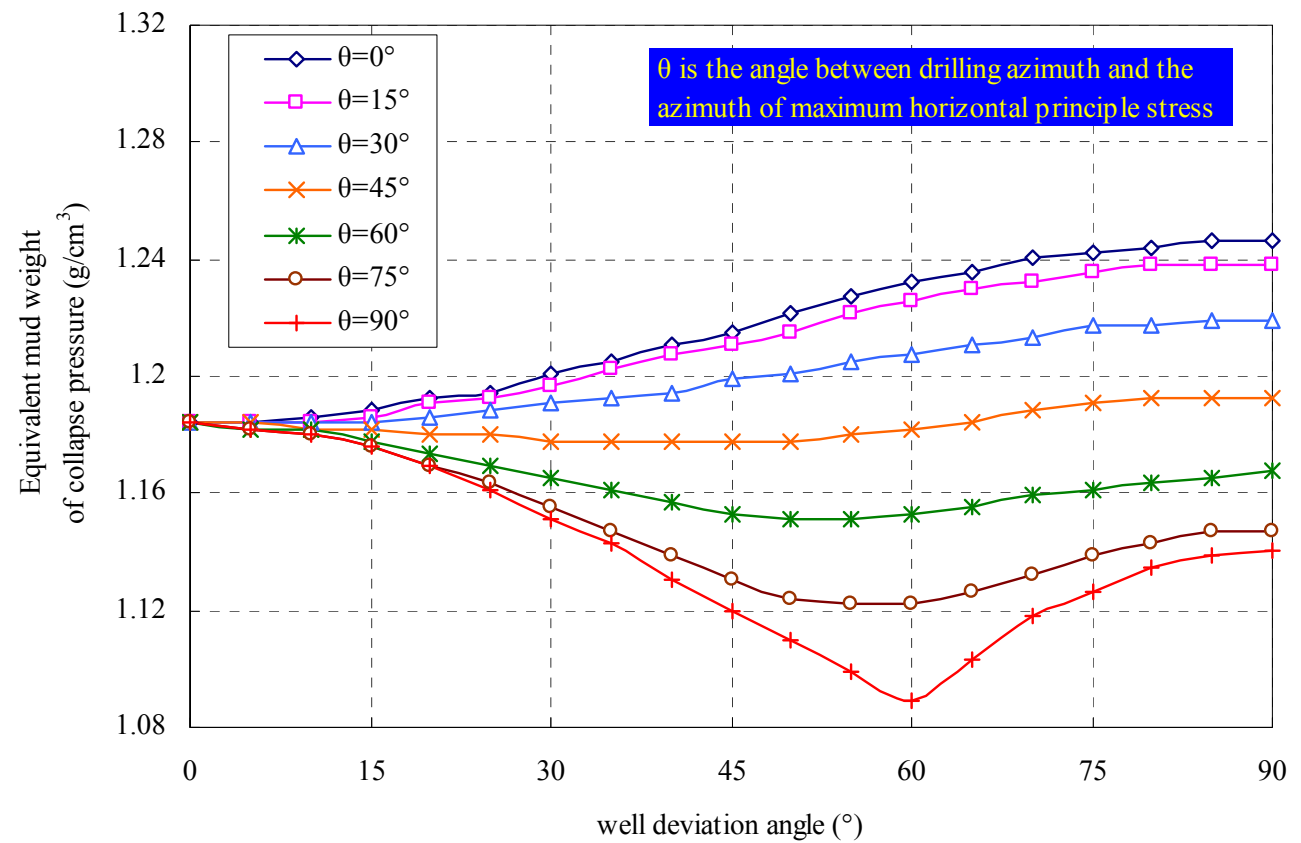

Fig. (4). Changes of equivalent mud density of collapse pressure with deviation and azimuth.

Where: $D_{h e}$-Equivalent diameter of eccentric annulus; $D_{p o}$-drilling string diameter.

The practice shows that cuttings bed is accumulated easily in ERW which has an important impact on circulating pressure loss. The conventional thickness calculation model of cuttings bed assumes the rock-breaking diameter is equal to bit diameter without considering collapsed rock because of hydration, so the solid concentration in annulus is relatively conservative. Combining with the analysis referred in the second chapter, we define the effective carrying cutting diameter as follows:

$D_{h}^{\prime}=D_{h}+2 k r$

Where: $r$-the influence radius of hydration; $k$-correction coefficient, $<1$.

Therefore, the thickness mode of cuttings bed [6] is modified as:

$T_{C B}=0.015 D_{h}^{\prime}\left(\mu_{e}+6.15 \mu_{e}^{0.3}\right)(1+0.587 \varepsilon)\left(V_{c}-V_{a}\right)$

Where: $\mu_{e}$-mud effective viscosity; $V_{c}$ - critical flow velocity in annulus.

Equation (11) was the theoretical calculation mode of circulating pressure loss in annulus without considering cuttings bed, which is not suitable for the ERW due to the existing cutting beds. So the empirical mode of circulating pressure loss in annulus was established through the regression analysis of the experiment data and the factor of cutting beds was taken into it [9]:

$\Delta p=\frac{0.0260686 h \Delta p_{a}}{f_{b}}\left[\frac{1000 V_{a}^{2}}{9.81\left(D_{h}-D_{p o}\right)(s-1)}\right]^{-1.25}+(1+0.00581695 h) \Delta p_{a}$

Where: $h$ - no dimension cuttings bed thickness; $s=\rho_{s} / \rho_{m}, \rho_{s}$-the density of cuttings.
According to the eq.14 to calculate the actual well bottom pressure during circulation, combining with that referred in chapter 1 , the upper limit value of safe mud density in ERW will be solved through the iterative method.

\section{FIELD APPLICATION}

We calculated the changes of the safe mud density window with different well deviation and azimuth angles, and also the safe mud density window considering the circulating pressure loss in annulus.

The calculation parameters are as followed: The vertical depth, $\mathrm{H}=1490 \mathrm{~m}$. Equivalent density of pore pressure, $\mathrm{Pp}=$ $1.03 \mathrm{~g} / \mathrm{cm}^{3}$. Equivalent density of in-situ stress, $\sigma_{H}=$ $1.99 \mathrm{~g} / \mathrm{cm}^{3}, \sigma_{h}=1.45 \mathrm{~g} / \mathrm{cm}^{3}, \quad \sigma_{v}=2.12 \mathrm{~g} / \mathrm{cm}^{3}$. Azimuth of maximum horizontal principle stress, $\omega=75^{\circ}$, and the displacement, $\mathrm{Q}=3.8 \mathrm{~m}^{3} / \mathrm{min}$.
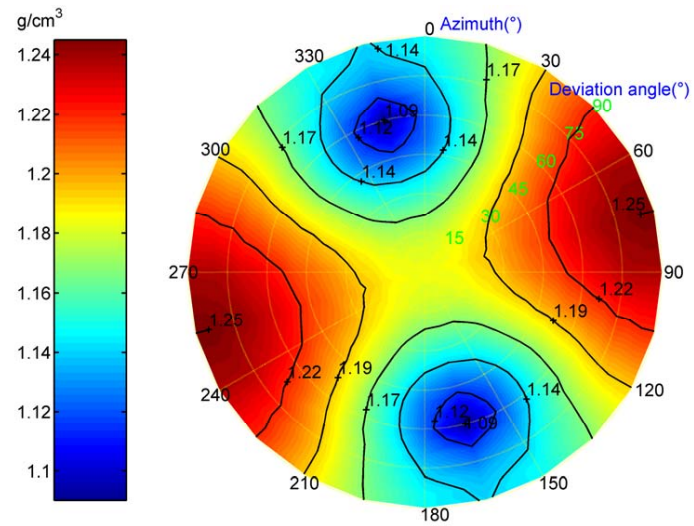

Fig. (5). The distribution of the equivalent mud density of collapse pressure $\left(\mathrm{g} / \mathrm{cm}^{3}\right)$. 


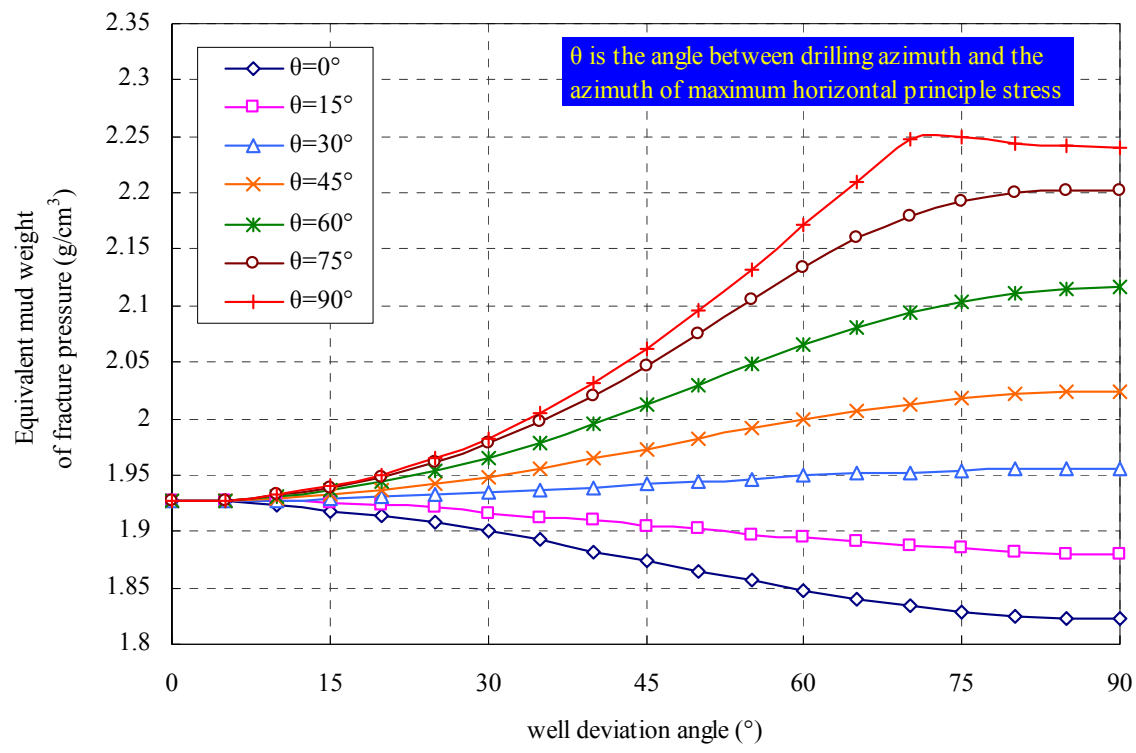

Fig. (6). Changes of equivalent mud density of fracture pressure with deviation and azimuth.

The changes of equivalent mud density of collapse pressure with different borehole deviation and azimuth are shown in Figs. (4 and $\mathbf{5}$ ). The collapse pressure is defined as the minimum mud column pressure to prevent borehole collapse. It can be obtained by the combination of $6,7,8,9$. The equivalent mud weight of collapse pressure is defined as the mud density which can produce the collapse pressure in fixed depth. In the actual drilling work, the collapse pressure was often converted into the equivalent mud weight to guide field selection of safety mud density. In Fig. (4), $\theta$ is the angle between drilling azimuth and the azimuth of maximum horizontal principle stress, and each of these curves reflects the equivalent mud density of collapse pressure with different borewell deviation angles under fixed borehole azimuth. Fig. (5) was formed by plotting the contour lines using interpolation method to show the equivalent mud density of collapse pressure of the borehole with any borewell deviation angle and azimuth angle. The results show that when drilling directional wells towards the azimuth of maximum horizontal principle stress, collapse pressure will be higher, and as the well deviation angle increased, collapse pressure will be higher, so when drilling horizontal well towards the azimuth of maximum horizontal principle stress, the risk of borehole collapse instability is bigger. In contrast, when drilling directional wells towards the azimuth of minimum horizontal principle stress, the risk of borehole instability is smaller.

The changes of fracture pressure with different borehole deviation and azimuth are shown in Figs. (6 and 7). The fracture pressure is defined as the maximum mud column pressure to prevent borehole collapse. It can be obtained by the combination of 6,10 . The equivalent mud weight of fracture pressure is defined as the mud density which can produce the fracture pressure in fixed depth. In the actual drilling work, the fracture pressure was often converted into the equivalent mud weight to guide field selection of safety mud density. In Fig. (6), $\theta$ is the angle between drilling azimuth and the azimuth of maximum horizontal principle stress, and each of these curves reflects the equivalent mud density of fracture pressure with different well deviation angles under fixed borehole azimuth. Fig. (7) was formed by plotting the contour lines using interpolation method to show the equivalent mud density of fracture pressure of the borehole with any well deviation angle and azimuth angle. The results show that when drilling directional wells towards the azimuth of maximum horizontal principle stress, fracture pressure will be lower, and as the well deviation angle increased, fracture pressure will be lower, so when drilling horizontal well towards the azimuth of maximum horizontal principle stress, the risk of borehole fracture instability is higher. Oppositely, when drilling directional wells towards the azimuth of minimum horizontal principle stress, the risk of borehole instability is smaller.

Through comprehensive analysis of the changes of collapse and fracture pressure with different borehole deviations and azimuth, we can find that when drilling directional wells towards the azimuth of maximum horizontal principle stress, collapse pressure will be higher and fracture pressure will be lower, and the risk of borehole instability is higher.
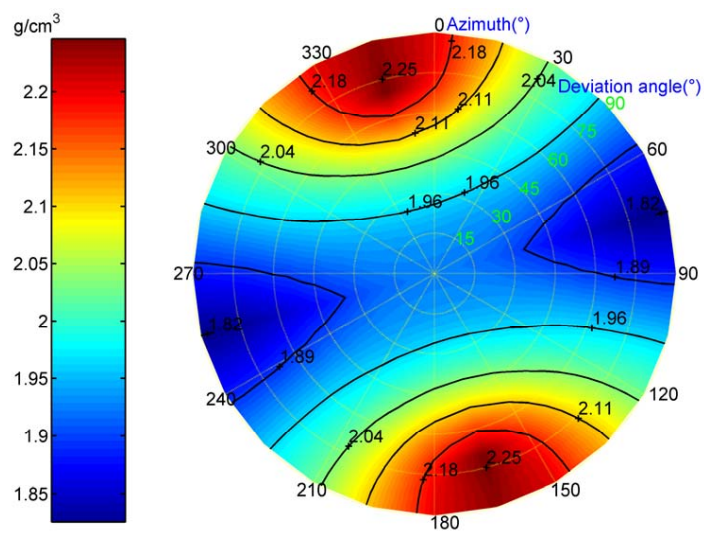

Fig. (7). The distribution of the equivalent mud density of fracture pressure $\left(\mathrm{g} / \mathrm{cm}^{3}\right)$. 


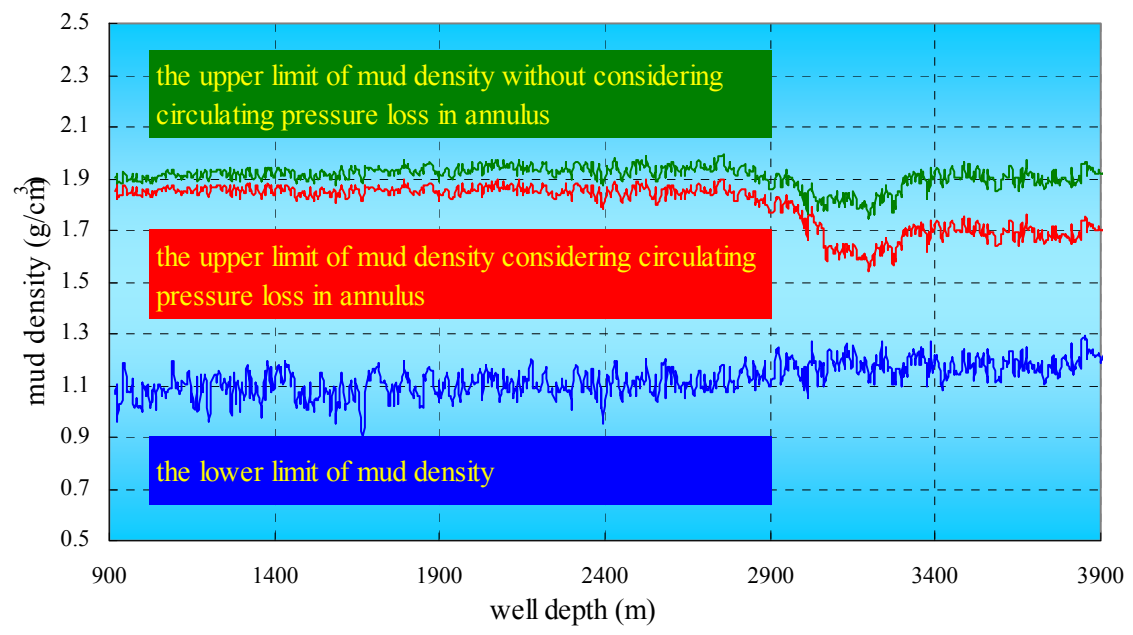

Fig. (8). The safe mud density window during the whole drilling process.

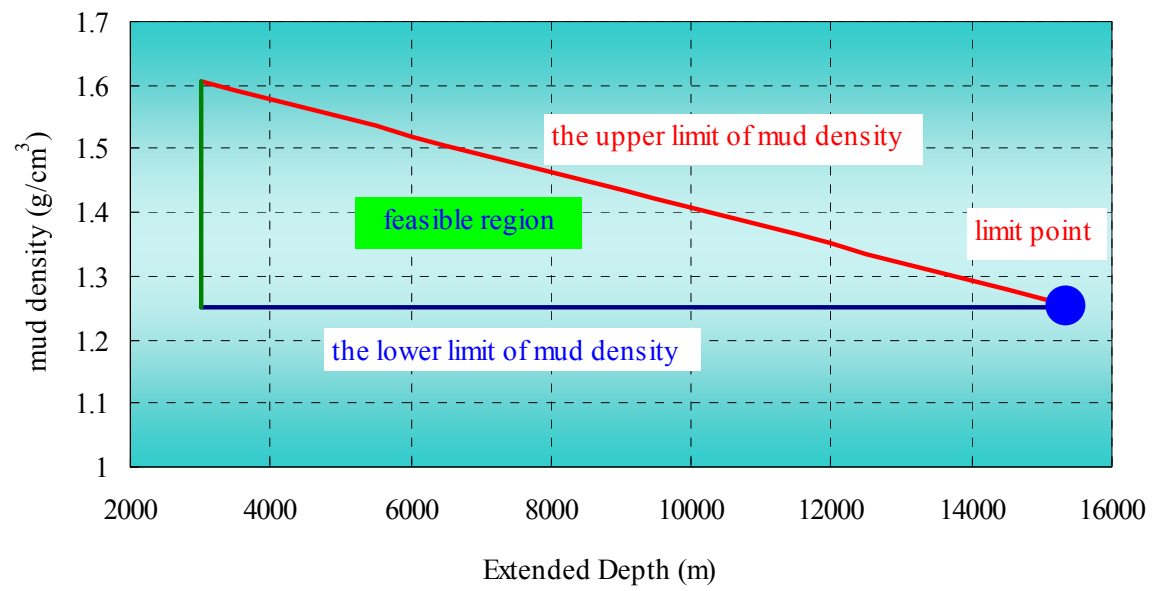

Fig. (9). The change of safe mud density window with extended depth.

The comparison of safe mud density window while considering and not considering the circulating pressure loss in annulus is shown in Fig. (8). The results showed that the upper limit value of mud density will decrease when considering the circulating pressure loss, and as the well depth increased, the decrease will be higher. When the upper limit value of mud density reduces to the value which equals to the collapse pressure, the limit depth of the ERW will be reached Fig. (9), and there will be no capability of borehole stability.

Research results were used in the ERW of some oilfield in China Bohai Sea oilfields, the maximum horizontal in situ stresses lies in the direction $\mathrm{N} 75^{\circ} \mathrm{E}$, and the well azimuth is $\mathrm{N} 240^{\circ} \mathrm{E}$. The calculated equivalent mud density of collapse pressure in the horizontal interval was $1.25 \mathrm{~g} / \mathrm{cm}^{3}$, but in order to avoid reservoir damage, the lower mud density $\left(1.10 \mathrm{~g} / \mathrm{cm}^{3}\right)$ was used, which cannot keep borehole stability effectively, so some drilling accidents occurred which needed some measures to deal with. In addition, in the highly-deviated well section (well deviation angle $85^{\circ}$ ), the calculated equivalent mud density of collapse pressure was $1.23 \mathrm{~g} / \mathrm{cm}^{3}$, and the used mud density was $1.23 \mathrm{~g} / \mathrm{cm}^{3}$, which can keep borehole stability effectively, so the drilling process in the section went smoothly. Finally, the vertical rate of the ERW was high to 2.3, and the horizontal displacement extended to $3460 \mathrm{~m}$, which was within the limited depth. The research results were successfully used to guide the drilling work.

\section{CONCLUSIONS}

1) Borehole stability of the ERW is related to well trajectory. In normal fault, the azimuth of minimum horizontal principle stress will be safer.

2) Combining the laboratory experiment, we discussed the change law of shale strength with time and space, and analyzed the influence radius of hydration. As time went on, the influence radius of hydration will be bigger and more and more rock around borehole will go into bore hole, which has important influence on cutting beds and circulating pressure loss in annulus.

3) The calculation mode of the safe mud density window for the ERW when considering the circulating pressure loss in annulus was established, in order to keep borehole stability during the whole drilling process. When considering the circulating pressure loss, the upper limit value of mud density will decrease and with the well 
depth increased, the safe mud density window will be narrower, which does not exist, the limit depth of the ERW will be reached, and there will be no capability of borehole stability.

\section{CONFLICT OF INTEREST}

The authors confirm that this article content has no conflicts of interest.

\section{ACKNOWLEDGEMENTS}

This work was supported by the Natural Science Foundation of China (No. 51174219).

\section{REFERENCES}

[1] J. Wei, "Application of drilling technology of ERW in Bohai sea oil field", Doctoral dissertation of Southwest Petroleum University, 2002.

[2] B.S. Aadnoy, and M.E. Chenevert, "Stability of highly inclined boreholes", SPE Drilling Engineering, vol. 2, no. 4, pp. 364-374, 1987.
[3] F.K. Mody, and A.H. Hale, "Borehole-stability model to couple the mechanics and chemistry of drilling-fluid/shale interactions", Journal of Petroleum Technology, vol. 45, no. 11, pp. 1093-1101, 1993.

[4] Y. Cheng, J. Yan, and G. Wang, "A Comprehensive Study of Wellbore Stability in Shale Formation and Its Application to Horizontal Drilling Operations", In: International Conference on Horizontal Well Technology, Alberta, Canada, Paper no.: SPE 37080, 1996.

[5] E. Van Oort, "On the physical and chemical stability of shales", Journal of Petroleum Science and Engineering, vol. 38, no. 3-4, pp. 213-235, 2003.

[6] F.S. Zhou, and C.S. Pu, "Study on predication of cutting bed thickness in eccentric annular in horizontal well", Petroleum Drilling Techniques, vol. 26, no. 4, pp. 17-19, 1998.

[7] Y. Jin, M. Chen, and G.H. Liu, "Wellbore stability analysis of ERWs", Journal of Geomechanics, vol. 5, no. 1, pp. 4-11, 1999.

[8] C.H. Yew, M.E. Chenevert, C.L. Wang, and S.U. Osisanya, "Wellbore stress distribution produced by moisture adsorption", SPE Drilling Engineering, vol. 5, no. 4, pp. 311-316, 1990.

[9] H.G. Wang, X.S. Liu, G. Ding, and H. Li, "Development of model for pressure drop in annular space of horizontal well", Journal of the University of Petroleum, China, vol. 20, no. 2, pp. 30-35, 1996.

(C) Kai et al.; Licensee Bentham Open.

This is an open access article licensed under the terms of the Creative Commons Attribution Non-Commercial License (http://creativecommons.org/licenses/by-nc/3.0/) which permits unrestricted, non-commercial use, distribution and reproduction in any medium, provided the work is properly cited. 